تهدف المجتمعات المتحضـرة الـى ممارسـة الرياضـة من أجل تحسين الحالة الصحية العامـة، وتطوير كفاءة الأداء، وتعديل أسلوب الحياة والوصول إلى الصحة الكاملة Wellness، مما يعني أن العائد البدني والوظيفي والنفسي هو عائد اقتصادي واجتماعي هام وحيوي من اجل التتمية البشرية وحياة الشعوب.

(أبو العلا عبد الفتاح وليلى صلاح، 1999)

وقد شهت نظم التعليم ومناهجه تحديات كبيرة في النصف الثاني من القرن العشرين ناتجة عن التطور المعرفي الهائل، والثورة التكنولوجية في المجال الصناعي، وتكنولوجيا الاتصال، مما أدى إلى ظهور اتجاهات حديثة في مجال التربية والتعليم لمواكبة تلك التطور، وكان من أحدث تلك الاتجاهات الدعوة إلى تبني مفهوم الجودة الثاملة في التعليم وإداراته بعد تطبيق هذا الاتجاه في عمل المؤسسات الإنتاجية، والخدمية وتحقبقها نجاحات كبيرة، وقد أصبحت الجودة تمثل حياة العصر وتقافته مما أوجب أن يؤسس لها في نظم التعليم على اعتبار أنه عملية إنتاجية تتعامل مع الإنسان، ويشكل عنصرا رئيساً فيها وكما يجب أن تكون المنتجات في المؤسسة الإنتاجية الصناعية، أو الخدمية متميزة، يجب أن يكون خريج المؤسسة التعليمية متميزاً وأن تكون الخدمات التي تقدمها المؤسسة التعليمة للتععلين تحقق الجودة الثناملة، لما سوف تحققه من عوائد تتموية بشرية واقتصادية واجتماعية ، وتقديمها الجودة التعليمية كأهداف تربوية وتعليمية يمكن قياسها. ( بهجت بهجت، 2002) (عطية محس، 2008)

ويلعب التقويم دورًا فعالاً ومؤثرًا في نوجيه عمليتي التعليم والتعلم وإثرائهما، فعملية التقويم وثيقة الارتباط بهاتين العمليتين نؤثر فيهما وتتأثر بهما في إطار المنظومة التعليمية المتكاملة . (صلاح الدين علام، 1997).

ونظرا لما ظهر على الساحة التربوية والعلمية في الآونة الأخيرة من اهتمام بجودة التعليم على مختلف أنواعه، وحرصاً على مسايرة التطور المستمر والدائم لتحسين العملية التعليمية ومواكبة التقام السريع في شتى العلوم المختلفة، حيث يجب أن يتم تقييم المقررات أول بأول وخاصـة إذا ما كانت هذه المقررات موضوعة حديثا، كما هو الحال بالنسبة لمقرر التربية البدنية بيرنامج الإعداد الجامعي لجامعة دار العلوم بالرياض الذي أنشئ حديثاً ليواكب التطور الحادث بالمملكة والذي من شأنه رفع مستوى اللياقة البدنية والاهتمام بممارسة الأنشطة البدنية وخاصة للطالبات، مما تستلزم منا عملية التقييم المستمر لهذه المقررات ومدى فاعليتها في تحقيق أهدافها المنشودة. وتعتبر المعايير إحدى الوسائل الموضوعية التي يُعتمد عليها في تقويم أداء الطلاب والطالبات، حيث يمكن من خلالها مقارنة وتفسير الدرجات المستخلصة من تطبيق الاختبارات والمقاييس والاستفادة منها في تطوير مسنوى اللياقة البدنية والفسيولوجية للطلاب والطالبات وهي إحدى الوسائل العلمية الضرورية لاستمرار التقدم العلمي بمختلف المبادين والتي من ضمنها المجال الرياضي.

ويصبح لدى الطلبة والطالبات الحافز لبذل مزيد من الجهد لتحقيق الأهداف التي وضعت للعملية التدريية والتعليمية، وعلى ذلك فإن الهدف الأساسي من عمليات التقييم لمحتوى المقررات هو التعرف على الأهداف الموضوعة وما تحقق منها ومالم يتحقق، وذلك باستخدام وسائل التقويم 
ومن منطلق إثراف الباحثة على وضع نوصيف مقررات التربية البدنية لجامعة دار العلوم بالرياض ولحداثة مثل هذه المقررات بالجامعات السعودية، ومن منطلق اتباع الجودة في متابعة وتقويم مفردات هذا المقرر بما يؤهله لتحقيق أهدافه المنشودة ومن ثم الوقوف على مدى تحقيقه لهذه الأهداف أو إجراء التطوير اللازم عليه، ظهرت فكرة هذه الدارسة في محاولة الباحثة التعرف على فاعلية وتأثير مقرر التربية البدنية (التربية البدنية "PE101") مرفق رقم (1) للطالبات على بعض المتغيرات الجسمية والفسيولوجية والبدنية الناتجة عن التدريب وأداء الجهد البدني في هذا المقرر

\section{هلف البحث:}

يهرف هذا البحث إلى التعرف على تأثثر مقرر التربية البدنية (PE101) بيرنامج الإعداد الجامعي (السنة التحضيرية) بجامعة دار العلوم بالرياض على بعض المتغيرات الجسمية والبدنية والفسيولوجية لدى الطالبات، وذلك من خلال تحقيق الأهداف الفرعية التالية: 1- - التعرف على فاعلية مقرر التربية البدنية على بعض المتغيرات الجسمية والبدنية لدى الطالبات قيد البحث. 2- التعرف على فاعلية مقرر التربية البدنية على بعض المتغيرات الفسيولوجية لاى الطالبات قيد البحث.

فروض البحث: 1- توجد فروق دالة إحصائياً في بعض المتغيرات الجسمية والبدنية لدى الطالبات قيد البحث لصالح القياس البعدي. 2- توجد فروق دالة إحصائياً في بعض المتغيرات الفسيولوجية لدى الطالبات قيد البحث لصالح القياس البعدي.

الدراسات المرتبطة:

قامت حنان صابر شعبان (1999) بدراسة بعنوان "تأثير منهاج التربية الرياضية الحديث للصف الأول الإعدادي على تتمية بعض عناصر

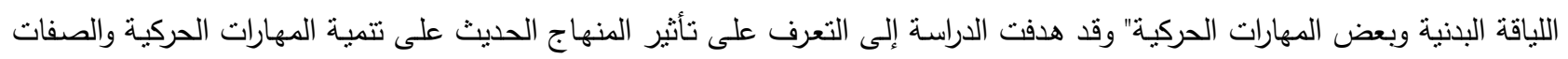

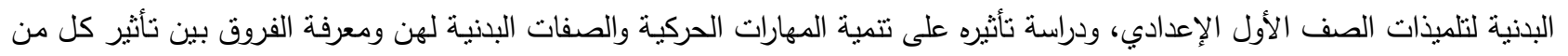
المنهاجين الحديث والمطور على تتمية المهارات الحركية، وقد استخدم المنهج التجريبي معتمداً على التصميم التجريبي لمجموعتني، إحداهما

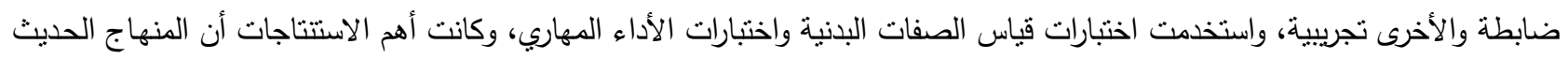
له تأثثر ايجابي وبنسبة كبيرة على اكتساب المهارات الحركية للوحدات التعليمية.

كما قامت منال محمد زكي (1999) بدراسة بعنوان "تطوير منهج الإيقاع الحركي بكلية التربية الرياضية للبنات بالإسكندرية" وقد هدفت

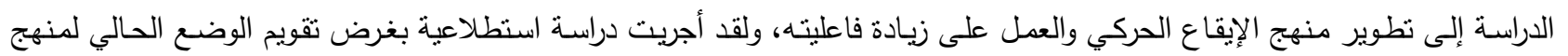

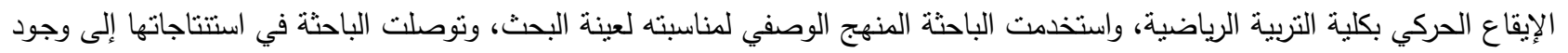
فروق دالة إحصائيا بين منوسطات درجات الطالبات في النطبيق القبلي ومتوسطات درجاتهن في النطبيق البعدي فيما يختص بالاختبارات

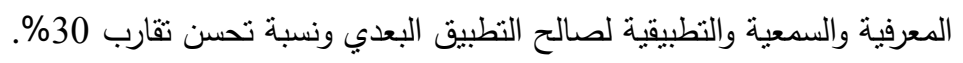

بينما قام محمد علي إبراهيم (2009) بدراسة "تقويم مستوى الكفاءة الفسيولوجية لطلاب كلية التربية الرياضية بجامعة صنعاء"، وقد كان هدف الدراسة التعرف على الكفاءة الفسيولوجية لطلاب كلية التربية الرياضية بجامعة صنعاء، وقد استخدم الباحث المنهج الوصفي، كما اشتملت 
عينة البحث على (193) طالب من كلية التربية الرياضية بصنعاء، وجاءت الاستتناجات أن طلاب المستويات الأعلى يتميزون بقدرات فسيولوجية أعلى من طلاب المستويات الأولى، ومنها الحد الأقصى لاستهالك الأكسجين، وقد أوصت الدراسة بضرورة إعادة النظر في برامج المقررات العملية لطلاب الكلية بغرض إجراء تتمية شاملة ومتزنة لجميع عناصر اللياقة البننية والفسيولوجية لطلاب الكلية وخاصفة في

$$
\text { متغيرات القدرة الهوائية (الحد الأقصى لاستهلاك الأكسجين المطلق والنسبي). }
$$

أما بالنسبة للاراسات الأجنبية فقد قام قام جين وانج (2012) بدراسة "ربط النظرية بالتطبيق كطرق فعالة من طرق التدريس لطلاب برامج

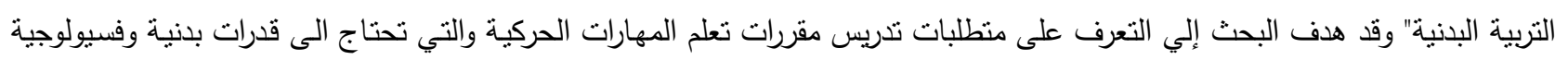
عالية، وخاصة إذا كانت لطلاب التربية البدنية، حيث أن الهدف من هذه المقررات هو ندريب الطلاب ليكونوا قادرين على تعليم هذه المهارات

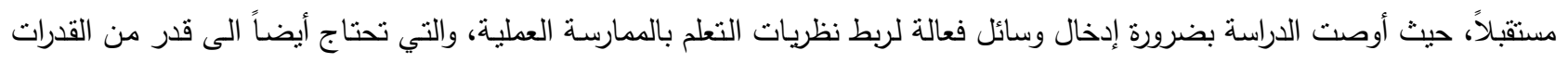
البدنية والفسيولوجية. بينما قام ساجد مم وأخرون . Sajad M, er al (2015) بدراسة بعنوان "تأثثر مقرر النتربية البدنية على الصحة النفسية للطلاب في جامعة

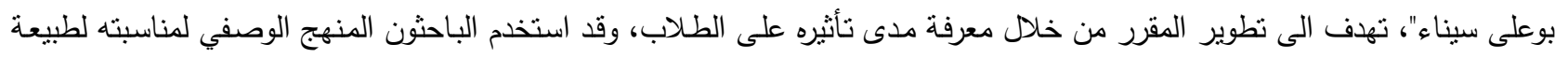

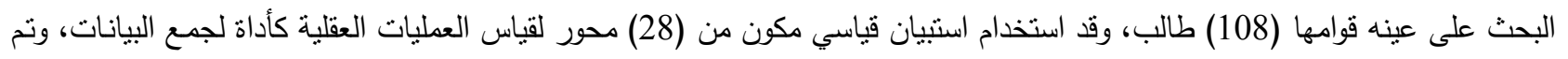

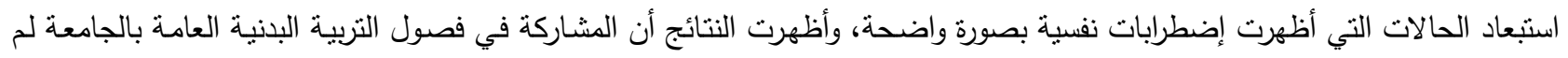
يكن كافي لإحداث تأثثر كبير على الصحة العقلية مما يوصي بتغيير المحتوى بصورة أفضل وأكثر تفاعلية مع الطلاب.

إجراءات البحث:

منهج البحث:

استخدمت الباحثة المنهج الوصفي نظرا لمناسبته لطبيعة البحث.

عينة البحث:

تم اختيار عينة البحث بالطريقة العدية العشوائية من طالبات الإعداد الجامعي المستجدات بجامعة دار العلوم بالرياض، واللاتي لم تمارسن أي نوع من الأنثطة البدنية من قبل وتراوحت أعمارهن بين (17 -19 سنة)، وقد بلغ عدد أفراد العينة (25) طالبة، وقد نم إجراء تجانس العينة من حيث الطول والوزن والسن.

جدول (1)

المتوسط الحسابي والانحراف المعياري والالتواء لعينة البحث

في متغيرات السن -الوزن -الطول 


\begin{tabular}{|c|c|c|c|c|}
\hline الالتواء & الانحراف المعياري & المتوسط الحسابي & وحدة القياس & المتغيرات \\
\hline 0.86 & 3.46 & 161.60 & سـم & الطول \\
\hline 0.65 & 7.08 & 67.92 & كجم & الـوزن \\
\hline 0.46 & 0.69 & 18.68 & سنة & السن الن \\
\hline
\end{tabular}

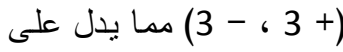

يتضح من الجدول السابق أن معاملات الالنواء لمتغيرات السن والوزن والطول قد تزاوحت ما بين

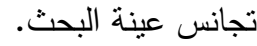

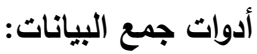

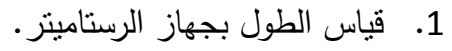

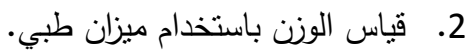

3. قياس معدل النبض وضغط الدم بجهاز OMRON. 4. قياس الكفاءة الهوائية عن طريق اختبار كوبر (Kilding E, 2006) (, et al, 2016William D) (1) 5. قياس السعة الحيوية Vital Capacity بجهاز السبيروميتر الجاف. (V) 2004Karlman W) 6. قياس المرونة باستخدام جهاز صندوق المرونة المعدل. (Chillón P, 2010) 7. قياس مكونات الجسم ونسبة الدهون بواسطة جهاز 770 .Inbody.

وفيما يلي توضيحاً للأسلوب التنفيذي لتطبيق البحث:

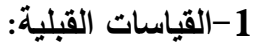

تم اجراء القياسات القبلية في بداية الفصل الدراسي الأول للعام الجامعي 2017/2016م يوم الأحد الموافق 2016/9/25، وذلك في الأسبوع الثاني بعد فترة التسجيل، بعد التأكد من عدم اداء الطالبات أي مجهود بدني غير ما يتم بالمحاضرات، وقد ثم قياس كل من الطول والوزن ثم قياس معدل النبض وضغط الدم الثرياني في وقت الراحة وقبل أداء أب جهد بدني، ثم قياس السعة الحيوية ونسبة المرونة وقياسات تركيب الجسم، ثم قامت عينة البحث بأداء الإحماء لمدة (10) دقائق وبعدها تم تطبيق اختبار كوبر لقياس الكفاءة الهوائية.

PE101 - 2 تطبيق مقرر التربية البدنية تم تطبيق المقرر الدراسي قيد البحث بداية من الأسبوع الثاني وحتى الأسبوع الثالث عشر من الفصل الدراسي الأول ، مرفق التقويم الأكاديمي مرفق رقم ( 2)، و هو مقرر يدرس في برنامج الإعداد الجامعي بالسنة الأولى بجامعة دار العلوم الأهلية بالرياض، ويقدم المقرر جزء عملي 
أساسي يحتوي على كرة السلة خلال الستة أسابيع الأولى الدراسية بجانب الجزء النظري التثقيفي في مجال النشاط البدني والصحة، وتم تقييم الجزء العملي من خلال استمارة تقييم مقننه مرفق رقم (3)، بينما نم الاختيار من عدة أنشطة أخرى للنصف الثاني من الفصل الدراسي من أنشطة (تنس الطاولة - الباليه للبنات - السباحة للجنسين) وذللك خلال الستة أسابيع الدراسية التالية، وقد تم تطبيق مقرر الباليه على جميع الثعب كمقرر اختباري هذا الفصل الدراسي حيث لم ينم اختيار أي من المقررات الاخرى في قسم الطالبات،وتم تقييم مهارات البالية بالاستعانة باستمارة تقييم مقتنه مرفق رقم (4) وهدف المقرر بشكل عام الى إكساب الطلبة والطالبات بعض المعلومات الصحية العامـة عن أهميـة ممارسـة الرياضة وسبل الوقاية من أمر اض قلة الحركة، وتأثير عدم ممارسة النشاط البدني على أجهزة الجسم، ومخاطر السمنة وكيفية إنقاص الوزن، وكذللك التعرف على مباديء الاسعافات الأولية وإكساب الطلبة والطالبات الخطوات الفنية للمهار ات العملية التي ينم تدريسها وقو انينها المختلفة،

وتم تقييم الجزئين العمليين وفقاً لاستمار ات تقييم مقننه لقياس المهارات التي تم تدريسها

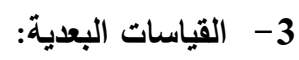

تم اجراء القياسات البعدية في الأسبوع الرابع عثر من الفصل الدراسي الأول للعام الجامعي 2017/2016م وذلك بعد انتهاء الفصل الدراسي وتطبيق مفردات المقرر بالكامل يوم الأحد 2017/1/1، بعد استبعاد الطالبات التي لم تحضر جميع المحاضرات، وقد تم إعادة قياس كل من معدل النبض وضغط الدم الثرياني في وقت الراحة وقبل أداء أي جهد بدني، ثم قياس السعة الحيوية ونسبة المرونة وقياسات تركيب الجسم، ثم قامت عبنة البحث بأداء الإحماء لمدة (10) دقائق وبعدها تم تطبيق اختبار كوبر لقياس الكفاءة الهوائية.

\section{المعالجات الإحصائية المستخدمة:}

استخدمت الباحثة في معالجة النتائج إحصائياً الأساليب النالية: (المنوسط الحسابي، الانحراف المعياري، معامل الالنواء، دلالة الفروق بطريقة ويلكوكسون للمجموعات المترابطة، كما اعتمدت الباحثة في معالجة بعض النتائج الإحصـائية على برنامج SPSS الإحصـائي، واستخدمت مستوى الدلالة (0.05) للتأكد من معنوية النتائج الإحصائية للبحث. 


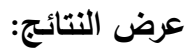

سوف ينم عرض النتائج التي تم التوصل إليها وفقاً للأسلوب الإحصائي المستخدم:

جدول (2)

المتوسطات الحسابية والانحرافات المعيارية والنسب المئوية للتحسن بين القياس القبلي والقياس البعدي في المتغيرات الجسمية والبلنية قيد البحث

\begin{tabular}{|c|c|c|c|c|c|c|}
\hline \multirow{2}{*}{$\begin{array}{c}\% \\
\text { بعد الأداء عن قبل الأداء } \\
\end{array}$} & \multicolumn{2}{|c|}{ بعدي } & \multicolumn{2}{|c|}{ قبلي } & \multirow{2}{*}{ وحدة القياس } & \multirow{2}{*}{ المتغيرات } \\
\hline & $\varepsilon$ & s & $\varepsilon$ & s & & \\
\hline 3.26 & 5.50 & 30.8 & 5.65 & 30.7 & 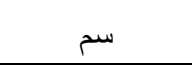 & المرونة \\
\hline $6.89-$ & 4.05 & 28.4 & 4.44 & 30.5 & نسبة مئوية & نسبة الدهون (Fat\%) \\
\hline
\end{tabular}

يتضح من جدول (2) ارتفاع المتوسط الحسابي للمرونة في القياس البعدي عن القياس القبلي، بينما انخفض المنوسط الحسابي للنسبة المئوية للاهون في القياس البعدي عن القياس القبلي.

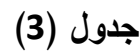

دلالة الفروق بين القياس القبلي والقياس البعدي في المتغيرات الجسمية والبذنية قيد البحث

\begin{tabular}{|c|c|c|c|c|c|}
\hline 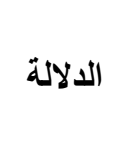 & $\begin{array}{c}\text { احتمالية الخطأ } \\
\text { P }\end{array}$ & $\mathbf{Z}$ & متوسط الرتب & القياس & المتغيرات \\
\hline \multirow{2}{*}{ غير دال } & \multirow{2}{*}{0.174} & \multirow{2}{*}{$1.361-$} & 5.33 & قبلي & \multirow{2}{*}{ المرونة } \\
\hline & & & 9.00 & بعدي & \\
\hline \multirow{2}{*}{ 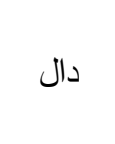 } & \multirow{2}{*}{$* 0.001$} & \multirow{2}{*}{$3.414-$} & 22.00 & قبلي & \multirow{2}{*}{ نسبة الدهون (Fat\%) } \\
\hline & & & 11.00 & بعدي & \\
\hline
\end{tabular}

يتضح من الجدول (3) أن هناك فروق دالة إحصائياً في متغير النسبة المئوية للدهون وذللك بين القياس القبلي والقياس البعدي لصالح القياس البعدي، بينما لم تكن هناك فروق ذات دلالة إحصائية في متغير المرونة، وذلك بين القياس القبلي والقياس البعدي. 
جدول (4)

المتوسطات الحسابية والانحرافات المعيارية والنسب المئوية للتحسن بين القياس القبلي والقياس البعدي في المتغيرات الفسيولوجية قيد

\begin{tabular}{|c|c|c|c|c|c|c|}
\hline \multirow{2}{*}{$\begin{array}{c}\% \\
\text { بعد الأداء عن قبل الأداء }\end{array}$} & \multicolumn{2}{|c|}{ بعدي } & \multicolumn{2}{|c|}{ قبلي } & \multirow{2}{*}{ وحدة القياس } & \multirow{2}{*}{ المتغيرات } \\
\hline & $\varepsilon$ & b & $\varepsilon$ & b & & \\
\hline $3.76-$ & 4.32 & 66.5 & 3.9 & 69.1 & نبضة / دقيقة & النبض \\
\hline $1.57-$ & 6.7 & 114.4 & 7.38 & 116.2 & مليمتر زئبق & ضغط الام الانقباضي \\
\hline $0.40-$ & 4.5 & 74.4 & 4.6 & 74.7 & مليمتر زئبق & ضغط الدم الانبساطي \\
\hline 4 & 0.46 & 2.6 & 0.47 & 2.5 & لتز & السعة الحيوية \\
\hline 2.44 & 67.6 & 1260 & 85.2 & 1230 & مسافة بالمنز & الكفاءة الهوائية \\
\hline
\end{tabular}

يتضح من جدول (4) ارتفاع المتوسط الحسابي للسعة الحيوية والكفاءة الهوائية في القياس البعدي عن القياس القبلي، بينما انخفض المتوسط الحسابي للنبض وضغط الدم الانقباضي والانبساطي في القياس البعدي عن القياس القبلي. (5) جدول

دلالة الفروق بين القياس القبلي والقياس البعدي في المتغيرات القسيولوجية قيد البحث

\begin{tabular}{|c|c|c|c|c|c|}
\hline الالالة & احتمالية الخطأ & $\mathbf{Z}$ & متوسط الرتب & القياس & المتغيرات \\
\hline \multirow{2}{*}{ دال } & \multirow{2}{*}{$* 0.00$} & \multirow{2}{*}{$3.533-$} & 8.50 & قبلي & \multirow{2}{*}{ النبض } \\
\hline & & & 0.00 & بعدي & \\
\hline \multirow{2}{*}{ غير دال } & \multirow{2}{*}{0.068} & \multirow{2}{*}{$1.826-$} & 5.50 & قبلي & \multirow{2}{*}{ ضغط الدم الانقباضي } \\
\hline & & & 6.83 & بعدي & \\
\hline \multirow{2}{*}{ غير دال } & \multirow{2}{*}{0.276} & \multirow{2}{*}{$1.089-$} & 3.50 & قبلي & \multirow{2}{*}{ ضغط الام الاتبساطي } \\
\hline & & & 2.88 & بعدي & \\
\hline \multirow{2}{*}{ غير دال } & \multirow{2}{*}{0.082} & \multirow{2}{*}{$1.739-$} & 6.10 & قبلي & \multirow{2}{*}{ السعة الحيوية } \\
\hline & & & 8.50 & بعدي & \\
\hline \multirow{2}{*}{ دال } & \multirow{2}{*}{$* 0.017$} & \multirow{2}{*}{$2.392-$} & 1.00 & قبلي & \multirow{2}{*}{ الكفاءة الهوائية } \\
\hline & & & 5.00 & بعدب & \\
\hline
\end{tabular}


يتضح من الجدول (5) أن هناك فروق دالة إحصائياً في متغيرات معدل النبض والكفاءة الهوائية وذلك بين القياس القبلي والقياس البعدي لصالح القياس البعدي، بينما لم تكن هناك فروق ذات دلالة إحصائية في متغيرات ضغط الدم الانقباضي والانبساطي والسعة الحيوية، وذلك بين القياس القبلي والقياس البعدي.

مناقشة وتفسير النتائج:

مناقثة وتفسير نتائج الفرض الأول والذي ينص على أنه "توجد فروق دالة إحصائياً في بعض المتغيرات الجسمية والبدنية لاى الطالبات قبل وبعد نطبيق مقرر التربية البدنية لصالح القياس البعدي".

بملاحظة جدول (2) يتضح أن النسبة المئوية للنغير في المرونة بين القياس البعدي عن القياس القبلي كانت (3.26\%) لصالح القياس البعدي، كما يتضح أن النسبة المئوية للتغير في نسبة الدهون بين القياس البعدي عن القياس القبلي قد كانت (- 6.89\%) لصالح القياس البعدي، كما يتضـح ارتفاع المتوسط الحسابي للمرونة في القياس البعدي عن القياس القبلي، بينما انخفض المتوسط الحسابي للنسبة المئوية للدهون في القياس البعدي عن القياس القبلي.

وبملاحظة جدول (3) يتضح وجود فروق دالة إحصائياً في متغير النسبة المئوية للاهون وذلك بين القياس القبلي والقياس البعدي لصالح القياس البعدي، بينما لم تكن هناك فروق ذات دلالمة إحصائية في متغير المرونـة، وذلك بين القياس القبلي والقياس البعدي، وتعزو الباحثة هذا الانخفاض في النسبة المئوية للدهون بالجسم إلى تأثثر الجهد البدني داخل المقرر العملي الذي تبذله الطالبات على انخفاض نسبة الدهون بالجسم، لما يحتويه من تمرينات هوائية لمدة تقارب الساعنين وبالتالي زيادة كمية الطاقة المصروفة من الجسم والتي قد تزيد عن الطاقة المكتسبة مما يؤدي الى انخفاض نسبة الدهون بالجسم وهذا ما أنشار إليه أبو العلا عبد الفتاح (2003)، واتفق معه هزاع الهزاع (2008)، بينما ارتفعت المرونة بشكل بسيط إلا أنها لم تكن دالة إحصائياً، وتعزو الباحثة ذلك إلى احتياج الطالبات إلى زيادة الاهتمام بعناصر اللياقة البدنية ومنها المرونة بشكل أكثر تركيزا داخل المقرر العملي بجانب النواحي المهارية، وهو ما أكدته أيضاً لوارا.أ وأخرون Laura A, et al (2012). ومما سبق يتضح تحقق صحة القرد الأول جزئياً. مناقثة وتفسير نتائج الفرض الثاني والذي ينص على أنه "توجد فروق دالة إحصائياً في بعض المتغيرات الفسيولوجية لدى الطالبات قبل وبعد تطبيق مقرر التربية البدنية لصالح القياس البعدي". بملاحظة جدول (4) يتضح أن النسبة المئوية للنغير في معدل النبض بين القياس البعدي عن القياس القبلي كانت (- 3.76\%) لصالح القياس البعدي، كما يتضح أن النسبة المئوية للتغير في ضغط الدم الانقباضي بين القياس البعدي عن القياس القبلي قد كانت (- 1.57\%) لصالح القياس البعدي، كما كانت النسبة المئوية للتغير في ضغط الدم الانبساطي بين القياس البعدي عن القياس القبلي (- 0.40\%) لصالح القياس البعدي، كما النسبة المئوية للنغير في السعة الحيوية بين القياس البعدي عن القياس القبلي (4\%) لصالح القياس البعدي، وقد كانت النسبة المئوية للتغير في الكفاءة الهوائية بين القياس البعدي عن القياس القبلي (2.44) لصالح القياس البعدي، كما يتضح ارتفاع المتوسط الحسابي للسـعة الحيويـة والكفاءة الهوائيسة في القياس البعدي عن القياس القبلي، بينمـا انخفض المتوسط الحسابي للنبض وضـغط الدم الانقباضـي والانبساطي في القياس البعدي عن القياس القبلي. 
وبملاحظة جدول (5) يتضح وجود فروق دالة إحصائياً في متغيرات معدل النبض والكفاءة الهوائية وذلك بين القياس القبلي والقياس البعدي لصالح القياس البعدي، بينما لم تكن هناك فروق ذات دلالة إحصائية في متغيرات ضغط الدم الانقباضي والانبساطي والسعة الحيوية، وذلك بين القياس القبلي والقياس البعدي، وتعزو الباحثة هذا الانخفاض في معدل النبض والكفاءة الهوائية إلى تأثثر الجهد البدني المبذول داخل المقرر العملي قبد البحث على التكيف الذي الحادث لعضلة القلب نوعا ما من جراء الاستجابات المنظمة والمكتسبة من خلال الانتظام بالمقرر العملي والذي يشتمل على مهارات كرة السلة والباليه المطبق على الطالبات وبما يحتويه من مهارات تتسم بالثدة المتوسطة مع التتوع في الأداء، والذي تطلب قيام القلب بضخ الدم وفقا لحاجة عضلات الجسم في أثناء قيامها بالمجهود البدني، مما أحدث زيادة في السعة القلبية والتنفسية رافقها انخفاض في معدل النبض أثناء الراحة، وهذه الحقيقة تشير إلى نجاح مهارات كلاً من كرة السلة والباليه وخاصة مهارات الباليه الدقدم للطالبات في صورة مقرر اختياري حيث أثثت درجات الطالبات في هذا المقرر مدى احساسهن وانجذابهن لهذا النوع من الأداء الحركي، حيث أن الباليه كأحد أنواع التعبير الحركي ليس فقط فنا مفعماً بالحيوية، ولكنه أيضاً يعتمد بشكل كبير على الاحساس الحركي وذلك كان محفز قوي للطالبات على بذل المزيد من الجهد أثناء المحاضرات مما أثر بصورة أكثر إيجابية لصالح الللياقة القلبية والتفسية، وهذا ما أكدت عليه صفية حمدي (2007)، واتفق معها ألان.سي . Alan Cebecca T (2010)، وأيضاً ريبيكا.ت (2012)، حيث أثنارا إلى نأثثير الجهد البدني على خفض معدل النبض في وقت الراحة وزيادة الكفاءة الهوائية.

بينما تعزو الباحثة عدم وجود فروق ذات دلالة إحصائية في متغيرات ضغط الدم الانقباضي والانبساطي والسعة الحيوية إلى احتياج الدقرر إلى زيادة عدد الساعات المعتمدة بـه وذلك عن طريق زيادة ساعة أخرى عملية، حيث أن عدد ساعات المقرر الحالي لا يكفي إلى تحسن هذه المتغيرات الفسيولوجية، مع النأكيد على الجانب العملي منه وخاصة المعتمد على مهارات الباليه لما لها من تأثثر هوائي، وهذا ما اتفق معه جيمس.م وأخرون James M, et al (2011) إلى أن ممارسة الأنشطة البدنية من شأنها أن تحسن من وظائف الجسم المختلفة عن طريق عمليات التكيف المختلفة وخاصة بالنسبة لوظائف الجهاز القلبي الوعائي والجهاز التتفسي. ومما سبق يتضح تحقق صحة الفرد الثاني جزئياً. 
الاستتناجات:

في ضوء نتائج البحث وحدود العينة وخصائصها والمنهج المستخدم وأسلوب التحليل الإحصائي المتبع أمكن التوصل إلى الاستتناجات التالية: 1. أدى المجهود البدني خلال الانظظام في دراسة مقرر التربية البدنية PE101 والمكون من مهارات كرة السلة والباليه إلى خفض النسبة المئوية للاهون بالجسم.

2. أدى المجهود البدني خلال الانظظام في دراسة مقرر التربية البدنية PE101 والمكون من مهارات كرة السلة والباليه إلى خفض معدل

$$
\text { النبض وزيادة الكفاءة الهوائية. }
$$

3. أدى المجهود البذني خلال الانتظام في دراسة مقرر التربية البدنية PE101 والمكون من مهارات كرة السلة والباليه إلى زيادة المرونة والسعة الحيوية وخفض ضغط الدم الانقباضي والانبساطي ولكن بشكل غير كافي.

$$
\text { استتادا إلى النتائج التي تم التوصل إليها في هذا البحث توصي الباحثة بالآتي: }
$$

1. إضافة ساعة معتمدة عملي للمقرر (ساعتين إتصال)، على أن تكون في موعد أخر خلال الأسبوع، حتى يمكن تحسين المتغيرات الجسمية واللياقة البننية والفسيولوجية لاى الطالبات.

2. زيادة مفردات مهارات الباليه داخل الدقرر، حيث لاحظت الباحثة زيادة اقبال الطالبات عليه، ولما له من تأثير ايجابي على تحسن

$$
\text { المتغيرات الجسمية والبننية والفسيولوجية. }
$$

3. ضرورة مراعاة أن يكون التقويم الفصلي مستمر وليس متقطع، لذا من المكن إضافة اختبار فصلي ثالث وخاصـة في المقررات

$$
\text { العملية لكي يمكن للقائم بالتدريس تصحيح عملية التعلم. }
$$

4. إجراء دراسات ممانلة تتبعية على مقرر التربية البدنية (PE102) ومقارنته بمستويات الطالبات بالمقرر الحالي. 


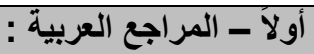

1. أبو العلا أحمد عبد الفتاح. (2003): فسيولوجيا الندريب والرياضة، دار الفكر العربي، القاهـرة. 2. أبو العلا أحمد عبدالفتاح، ليلى صلاح الدين سليم. (1999): الرياضة و المناعة، دار الفكر العربي، القاهرة.

3. بهجت عطية بهجت. (2002): إدارة الجودة الثـاملة كمدخل لتطوير ادارة الاندية الرياضية المصرية في ضوء التحولات العالمية

المعاصرة، رسالة دكتوراه غبر منشورة، كلية التربية الرياضية للبنين، جامعة حلوان.

4. حنان صابر شعبان. (1999): ثأثير منهاج التربية الرياضية الحديث للصف الأول الإعدادي علي نتمية بعض عناصر اللياقة البدنية

وبعض المهارات الحركية، رسالة ماجستير غير منشورة، جامعة الزقازيق، مصر •

5. صفية أحمد محي الدين حمدي. (2007): التصميم الإبتكاري لعروض التعبير الحركي ط1، القاهرة: مكتبة الأنجلو الأمريكية. 6. صلاح الدين محمود علام. (1997): دليل المعلم في تقويم الطلبة في الدراسات الاجتماعية، دار الفكر العربي، القاهرة. 7.

8. ليلى عبد العزيز زهران. (1991): المناهج في التربية الرياضية، دار زهران للنشر، القاهرة.

9. محمد صبحي حسانين. (1998): أطلس تصنيف ونوصيف الأجسام؛ مركز الكتاب للنشر، القاهرة.

10. محمد علي إبراهيم. (2009): تقويم مستوى الكفاءة الفسيولوجية لطلاب كلية التربية الرياضية بجامعة صنعاء، رسالة ماجستير غير

منشورة، جامعة حلوان، مصر .

11. منال محمد زكي. (1999): نطوير منهج الإيقاع الحركي بكلية التربية الرياضية للبنات بالإسكندرية، رسالة ماجستير غير منشورة،

جامعة الإسكندرية، مصر .

12. هزاع محمد الهزاع. (2008): فسيولوجيا الجهد البدني (الأسس النظرية والاجراءات المعلمية للقياسات الفسيولوجية)، الرياض: جامعة

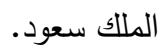


13. Alan C. (2010): Measurement and Evaluation in Physical Education and Exercise Science, Illinois State University.

14. Chillón P, Castro-Piñero J, Ruiz R, Soto M, Carbonell-Baeza A, Dafos J, et al. (2010) Hip flexibility is the main determinant of the back-saver sit-and-reach test in adolescents. Journal of sports sciences, 28 (6), p. 641-648.

15. James M, Allen J, James D, Dale M. (2011): Measurement and Evaluation in Human Performance, 4th Edition, department of kinesiology, health promotion and recreation, University of North Texas at Denton.

16. Jin W. (2012): Connecting Theory to Practice - Effective ways of Teaching Motor Learning Courses for Undergraduate Physical Education Students, International Journal of Physical Education, Fitness and Sports-IJPEFS, Vol.1. No.4. ISSN 2277-5447.

17. Karlman W, James E. Hansen E, Darry Y. Sue S, et al. (2004): Principles of Exercise Testing and Interpretation, Lippincott Williams \& Wilkins, Philadelphia, ISBN 7-7817-4876-3; 612. USA.

18. Kilding E. (2006): Measuring and predicting maximal aerobic power in international-level intermittent sport athletes. The Journal of Sports Medicine and Physical Fitness, 46 (3), p. 366-72.

19. Laura A, Louisa W, Lorraine C. (2012): Continuing professional development for students and teachers of physical education in health-related practices, European Physical Education Review.

20. Rebecca T. (2012): Physiological Tests for Elite Athletes, 2nd Edition, Australian Institute of Sport, journals of human kinetics, Australia.

21. Sajad M, Mahmood H, Amir R, Saeed N, Alireza. (2015): The Effects of Physical Education Course on Mental Health of Students in Bu-Ali Sina University, Hamedan-Iran, Int J Pediatr, Vol.3, N.2-1, Serial No.15.

22. William D, Victor L, Frank I. (2016): Essentials of Exercise Physiology, 5th edition, Philadelphia: Lippincott Williams \& Wilkins. 
الملخص :

\section{ملخص البحث باللغة العربية :}

يلعب التقويم دورًا فعالاً ومؤثرًا في توجيه عمليتي التعليم والتعلم وإثرائهما، فعملية التقويم وثيقة الارتباط بهاتين العملينين تؤثز فيهما وتتأثر بهما في إطار المنظومة التعليمية المتكاملة، حيث يجب أن يتم تقييم المقررات أول بأول وخاصة إذا ما كانت هذه المقررات موضوعة حديثا، كما هو الحال بالنسبة لمقرر التربية البدنية بيرنامج الإعداد الجامعي لجامعة دار العلوم بالرياض والذي من شأنه رفع مستوى اللياقة البدنية والاهتمام بممارسة الأنشطة البدنية وخاصة للطالبات، مما تستنزم عملية التقييم المستمر لهذه المقررات ومدى فاعليتها في تحقيق أهدافها المنشودة، ومن منطلق إثراف الباحثة على وضع توصيف مقررات التربية البدنية لجامعة دار العلوم بالرياض ولحداثة متل هذه المقررات بالجامعات السعودية،

ومن منطلق اتباع الجودة في متابعة وتقويم مفردات هذا المقرر بما يؤهله لتحقيق أهدافه المنشودة ومن ثم الوقوف على مدى تحقيقه لهذه الأهداف أو إجراء النطوير اللازم عليه، ظهرت فكرة هذه الدارسة في محاولة الباحثة التعرف على فاعلية مقرر النربية البدنية PE101 للطالبات على بعض المتغيرات الجسمية والفسيولوجية والبدنية الناتجة عن التدريب وأداء الجهد البدني في هذا المقرر، وقد دلت النتائج على أن تأثثر المجهود البدني خلال الانتظام في دراسة مقرر التربية البدنية PE101 والمكون من مهارات كرة السلة والباليه في خفض النسبة المئوية للاهون بالجسم، ومعدل النبض وزيادة الكفاءة الهوائية لدى الطالبات، وقد أوصت الدراسة بزيادة عدد الساعات المعتمدة للمقرر وزيادة مفردات مهارات 
The evaluation process is closely related to the integrated learning system. Courses must be evaluated especially if these courses are newly established, as is the case with a course of physical education in the university preparation program of the University of Dar Al Uloom in Riyadh, which will raise the level of physical fitness and interest in the exercise of physical activities especially for students, which necessitates the process of continuous evaluation of these courses and their effectiveness in achieving the desired goals. In order to follow the quality of the follow-up and evaluation of the course contents in order to qualify the desired goals and then to determine the extent of achieving these goals or the necessary development of it, The idea of this study appeared in the researcher's attempt to recognize the effectiveness of the physical education course PE101 for students on some physical and physiological variables resulting from training and physical exertion in this course. The results showed that the effect of physical exertion during regularity in the study of physical education PE101, which consists of the skills of basketball and ballet in reducing the percentage of body fat, pulse rate and increase the aerobic efficiency of students. The study recommended to increase the number of credit hours of the course and increase Ballet contents. 